\title{
Evaluación de la calidad del agua de la vereda Río Suárez de Puente Nacional, Santander
}

Water quality evaluation ot the rural area of Río Suárez of Puente Nacional, Santander

Lucía Constanza Corrales Ramírez ${ }^{1}$, Yurley Natalia Santamaria Mosquera ${ }^{2}$, Dario Alberto Luccioli Peña ${ }^{3}$, Miguel Angel Castañeda Casas ${ }^{4}$

\section{Resumen}

Objetivo. Determinar la calidad del agua que abastece a la población de la Vereda Rio Suarez del municipio de Puente Nacional por medio del cálculo del índice de riesgo de la calidad del agua (IRCA). Métodos. Se tomaron 10 muestras de diferentes puntos de la red de distribución del agua veredal, se realizó análisis físico-químico y microbiológico por técnica de filtración por membrana bajo parámetros del Instituto Nacional de Salud. Resultados. El análisis físico-químico mostró cuantificación de hierro elevado y nivel de turbiedad inadecuado lo que puede afectar el sabor y el aspecto del agua. El recuento de coliformes totales fue $>300 \mathrm{UFC} / 100 \mathrm{ml}$, , con identificación de Escherichia coli, Klebsiella oxytoca, Pseudomonas aeruginosa y Enterococcus entre otras, habitantes de suelo y aguas que pueden ser causantes de infecciones gastrointestinales e infecciones urinarias, resultados que indican que el agua no es apta para consumo humano.

Palabras claves: calidad del agua, análisis microbiológico, análisis físico-químico, coliformes totales, coliformes fecales.

\footnotetext{
1. Docente Programa Bacteriología y Laboratorio Clínico.

Número de certificación CvLac: 000048264120121119123

ORCID: https://orcid.org/0000-0002-2398-348X

2. Hospital Regional de Vélez - Santander.

Número de certificación CVLAC es: 00017431912019918188

ORCID: https://orcid.org/0000-0002-0740-4142

3. Hospital Central de la Policia.

Número de certificación CvLAC: 000174319620199181832

ORCID: https://orcid.org/0000-0002-1716-2327

4. Laboratorio COLCAN.

Número de certificación CvLac: 000174317920199181750

ORCID: https://orcid.org/0000-0003-2985-3114
} 


\section{Abstract}

Objective. To determine the quality of the water that supplies the population of the Vereda Rio Suarez of the municipality of Puente Nacional through the calculation of the risk index of water quality (IRCA). Methods. 10 samples were taken from different points of the water distribution network, physical-chemical and microbiological analysis was performed by membrane filtration technique under parameters of the National Institute of Health. Results. The physical-chemical analysis showed high iron quantification and inadequate turbidity level that can affect the taste and appearance of the water. The total coliform count> $300 \mathrm{CFU} / 100 \mathrm{ml}$., with identification of Escherichia coli, Klebsiella oxytoca, Pseudomonas aeruginosa and Enterococcus among others that inhabit soils and waters and can cause gastrointestinal infections and urinary infections and is not suitable for human consumption.

Keywords: water quality, microbiological analysis, physical-chemical analysis, total coliforms, fecal coliforms

\section{Introducción}

Colombia es uno de los países con mayor número de recursos hídricos en el mundo, cuenta con varios tipos de agua: lluvia, superficial, subterránea, marina, oceánica y agua de alimentación glacial; es un recurso básico y un bien de uso público, no obstante en el proceso de desarrollo económico, se incrementan las actividades que requieren el uso intensivo del agua, por lo cual las problemáticas ambientales asociadas a este recurso también aumentan. Dentro del agua superficial se encuentran los ríos de agua dulce que fluyen en la zona continental, de las partes altas hacia las bajas; desde los pequeños arroyos que carecen de nombre, hasta los grandes ríos como el Amazonas (1).
El río Suárez es una fuente de agua muy importante en los departamentos de Boyacá y Santander, nace en la Laguna de Fúquene, finalmente desemboca en el río Sogamoso. En las últimas décadas se han descrito casos relacionados con contaminación que afecta este recurso (2).

Esta descrito que el uso de agua no apta lleva a la aparición de enfermedades generadas por la ingesta de microorganismos patógenos. La contaminación se puede dar de diferentes formas: consumo directo del líquido, consumo de alimentos regados con ésta, contacto con fómites o excretas de humanos y animales y contaminación química, y en cualquier caso generan consecuencias para la salud en el humano (3). 
El agua apta para consumo ha sido definida en las Guías de Calidad del Agua de Bebida de la Organización Mundial de la Salud - OMS, como "adecuada para consumo humano y para todo uso doméstico habitual, incluida la higiene personal”. (4) Para ello es importante que el agua que consumen en las viviendas cuente con las características apropiadas definidas en el decreto 2115 de 2007. La mayor parte de las enfermedades prevalentes en los países en desarrollo, donde el abastecimiento de agua y el saneamiento son deficientes, son causadas por bacterias, amebas, virus $y$ helmintos (5).

En el mundo se reportan numerosos casos de enfermedades relacionadas con la calidad del agua, como consecuencia de deficiencias en el tratamiento del agua o por la pérdida de la integridad de la red de distribución de agua (6).

En Génova en el año 1993, la Unión Europea elaboró la Directiva 98/83/EC acerca de la calidad del agua para el consumo humano, adoptada por el Consejo el 3 de noviembre de 1998. Esta fue elaborada mediante la revisión de los valores de los parámetros de la antigua Directiva del Agua Potable de 1980, haciéndolos más estrictos de acuerdo con los últimos conocimientos científicos disponibles y la información ofrecida por las directrices de la OMS y del Comité Científico de Toxicología y Ecotoxicología (4).

Esta nueva Directiva proporcionó una base sólida tanto para los consumidores en la Unión Europea como para los proveedores de agua potable, permitiendo el establecimiento de los estándares europeos de la calidad del agua potable, los cuales son referencia internacional para el establecimiento de estándares y seguridad del agua potable (7). En EEUU la agencia de Protección Ambiental-EPA (Environmental Protection Agency) creó una ley de agua limpia (CWA, por sus siglas en inglés) que es fundamental en la protección de la calidad de las aguas superficiales en los Estados Unidos (8). En Colombia la resolución 2115 del 2007 es la que indica las condiciones aceptables de calidad del agua potable. Además de contar con un manual para la toma de muestra de agua potable estandarizado por el Instituto Nacional de Salud.

Existe gran variedad de agentes patógenos como bacterias, hongos y virus. Las bacterias patógenas oportunistas se pueden encontrar como parte de la flora de los sistemas acuáticos, estas bacterias por lo general producen enfermedades en individuos susceptibles o inmunosuprimidos, algunas de éstas son: Aeromonas spp, Campylobacter, Escherichia coli y Mycobacterium.

Colombia es uno de los países con mayor número de recursos hídricos en el mundo, riqueza hídrica que se ve representada por sus extensas redes de aguas atribuidas a su ubicación geográfica y relieve, condiciones que son favorables para la existencia de un importante número de cuerpos 
de agua lenticos (aguas estancadas como lagos y pantanos) y enormes extensiones de humedales (9) entre estas redes de agua se encuentra el rio Suárez.

El río Suárez, nace en la Laguna de Fúquene en los límites de los departamentos de Cundinamarca y Boyacá, a una altura de 3000 m.s.n.m., su cuenca posee una extensión de $9823 \mathrm{Km} 2$, de los cuales a Santander le corresponde el $35.25 \%$. Su caudal medio multianual es de $195 \mathrm{~m} 3 / \mathrm{seg}$. (10). El Área de Desarrollo Rural de la Hoya del Río Suárez la conforman 13 municipios, 5 en Boyacá, Chitaraque, Moniquirá, San José de Pare, Santana y Toguí y 8 municipios en Santander, Barbosa, Chipatá, Guavatá, Güepsa, Puente Nacional, San Benito, Suaitá y Vélez (11).

Desde hace décadas el río ha estado sometido a focos de contaminación, de los cuales existen reportes que involucran no solo al río, sino a los acueductos que se abastecen del mismo. En 1996 el periódico el Tiempo, publicó el artículo "RÍO SUÁREZ FOCO DE INFECCIÓN", donde refieren el vertimiento de las aguas negras del río Chiquinquirá al río Suárez, convirtiéndolo en una verdadera alcantarilla, problema que se venía presentando desde varios años atrás. Los más perjudicados con esta situación eran los habitantes ubicados a lo largo de la ribera, en un tramo superior a los 20 kilómetros, comprendido desde el sitio La Balsa en jurisdicción de Chiquinquirá, cruzando por el municipio de Saboyá, hasta llegar al corregimiento de Garavito, en límites con el departamento de Santander (12). Posteriormente en 1997 en un estudio realizado por la Universidad Nacional, se afirma que no es apto ni siquiera para actividades recreativas; a pesar de ello, en época de sequía, los habitantes de Güepsa o Barbosa (Santander), el mayor núcleo urbano de la Hoya, se surten de sus aguas (13).

Estas aguas no son aptas para consumo humano por la presencia de coliformes fecales. Además, el agua no es apta para riego, debido a que puede generar problemas sanitarios a la comunidad que consuma frutas con cáscara, hojas y tallos de hortalizas sin cocinar. Si se utiliza las aguas del río como destino final de los desechos, se debe determinar la carga crítica, es decir, la medida en que éste estaría en condiciones de resistir la entrada de contaminantes específicos sin que a largo plazo se produzcan cambios en los comportamientos o procesos de dicho ecosistema. Esta problemática del recurso agua al igual que la del suelo genera muchos conflictos para su uso (14).

En el ańo 2012 la Alcaldía de Puente Nacional puso en alerta a su comunidad sobre el envenenamiento de las aguas del río en una entrevista para el canal Caracol, en la cual el Alcalde electo en ese año, el señor José David Beltrán informó "el día miércoles 22 de febrero, en las horas de la tarde se detectó una contaminación en donde se presentaron en la superficie del río unos peces muertos y en estado de descomposición los cuales han sido tomados y enviados 
a la secretaria del departamento. En la Secretaria de Salud, allá se están haciendo los diferentes análisis y probablemente se demoren unos 15 días" (15).

Más tarde en el año 2014, se da una nueva alerta en varios municipios por contaminación del río Suárez, un volcamiento en el corregimiento de Garavito en el departamento de Boyacá de un tracto camión que transportaba petróleo alertó a los municipios que se abastecían del agua del río Suárez, haciendo un llamado en ese entonces a las poblaciones sobre evitar el consumo de estas aguas (16).
Según el Instituto de Hidrología, Meteorología y Estudios Ambientales (IDEAM) indica que hasta el día de hoy no se han realizado estudios acerca de la calidad del agua para consumo humano que llega a las viviendas en la vereda Río Suárez de Puente Nacional, Santander (17).

\section{Materiales y métodos}

La toma de muestra, se realizó en la vereda Río Suárez del municipio de Puente Nacional - Santander, en temporada de lluvia.

Figura 1. Mapa ubicación geográfica vereda Río Suárez (Puente Nacional - Santander).

Localidad: Vereda Río Súarez

Municipio: Puente Nacional, Santander.

Latitud: 5.86111 Longitud: -73.6822

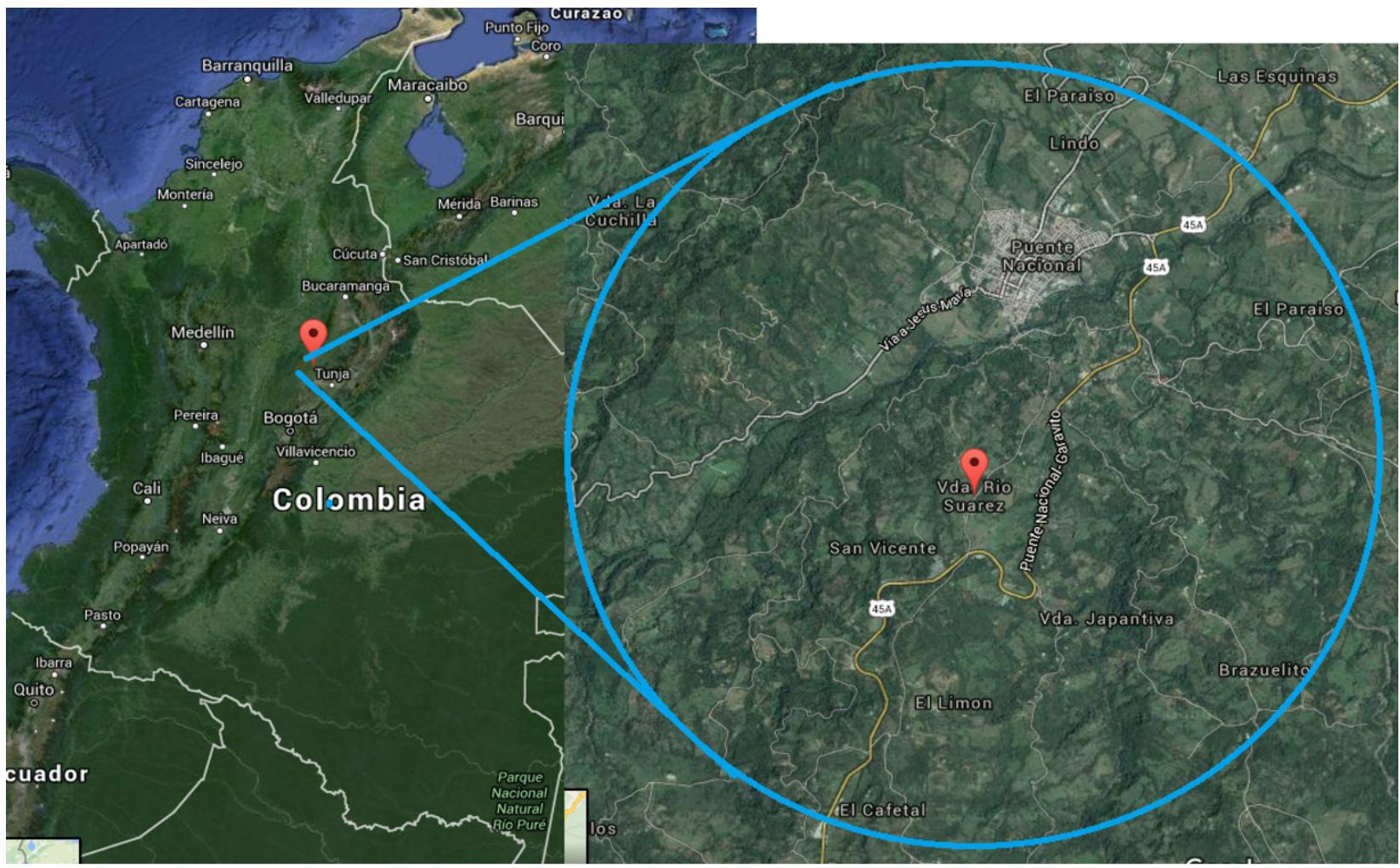

Fuente: www.google.com.co/maps (18). 
El agua para el estudio se recolectó en 10 botellas de plástico con capacidad para 3 litros, a la cuales se les realizó la preparación para examen microbiológico y la técnica de recolección se hizo conforme a la resolución 811 de 2008 y los protocolos establecidos en el manual de toma de muestras agua del Instituto Nacional de Salud (19). De cada una de las 10 muestras se recogió 3 litros y su distribución fue la siguiente: 3 de fuentes naturales y 7 de las casas de la vereda, con el fin de relacionar las características del agua antes y después de entrar a la red de distribución en la vereda del rio Suarez y se recolecto una muestra adicional de 1 litro, en frasco de plástico color ambar, facilitados por el laboratorio Hidrolab y debidamente preparado para el análisis físico químico que correspondió a la casa 1 . Los puntos de muestreo se describen en la tabla 1 .

Tabla 1. Puntos de muestreo.

\begin{tabular}{|c|c|c|}
\hline No & Sitio de análisis fuente natural & Coordenada \\
\hline 1 & Quebrada Otero & $\begin{array}{l}\text { 5o } 49^{\prime} 14.0 ” \mathrm{~N} \\
73^{\circ} 40^{\prime} 56.2^{\prime \prime} \mathrm{W}\end{array}$ \\
\hline 2 & Quebrada Villamil & $\begin{array}{l}\text { 50 } 50^{\prime} 19.4 ” \mathrm{~N} \\
73^{\circ} 41^{\prime} 11.7^{\prime \prime} \mathrm{W}\end{array}$ \\
\hline 3 & Quebrada la Angula & $\begin{array}{l}\text { 5o } 51^{\prime} 18.0 ” \mathrm{~N} \\
73^{\circ} 41^{\prime} 17.3^{\prime \prime} \mathrm{W}\end{array}$ \\
\hline No & Sitio de análisis de viviendas & Coordenada \\
\hline 4 & Casa 1 (Tomada del grifo) & $\begin{array}{l}5^{\circ} 51^{\prime} 25.0^{\prime \prime} \mathrm{N} \\
73^{\circ} 40^{\prime} 57.7^{\prime \prime} \mathrm{W}\end{array}$ \\
\hline 5 & Casa 2 (Tomada del grifo) & $\begin{array}{l}\text { 5o 48'04.4” N } \\
73^{\circ} 41^{\prime} 14.5^{\prime \prime} \mathrm{W}\end{array}$ \\
\hline 6 & Casa 3 (Tomada del grifo) & $\begin{array}{l}\text { 5० 48'04.9” N } \\
73^{\circ} 41^{\prime} 14.2^{\prime \prime} \mathrm{W}\end{array}$ \\
\hline 7 & Casa 4 (Tomada del grifo) & $\begin{array}{l}\text { 5o } 49^{\prime} 07.3 ” \mathrm{~N} \\
73^{\circ} 40^{\prime} 50.9^{\prime \prime} \mathrm{W}\end{array}$ \\
\hline 8 & Casa 5 (Tomada del grifo) & $\begin{array}{l}\text { 50 49’ } 07^{\prime \prime} \mathrm{N} \\
73^{\circ} 40^{\prime} 51.2^{\prime \prime} \mathrm{W}\end{array}$ \\
\hline 9 & Casa 6 (Tomada del grifo) & $\begin{array}{l}5^{\circ} 49^{\prime} 09^{\prime \prime} \mathrm{N} \\
73^{\circ} 40^{\prime} 53^{\prime \prime} \mathrm{W}\end{array}$ \\
\hline 10 & Casa 7 (Tomada del grifo) & $\begin{array}{l}5^{\circ} 50^{\prime} 03^{\prime \prime} \mathrm{N} \\
73^{\circ} 40^{\prime} 58^{\prime \prime} \mathrm{W}\end{array}$ \\
\hline
\end{tabular}

Fuente: Elaboración propia. 
Figura 2. Recolección de agua quebrada la Angula.

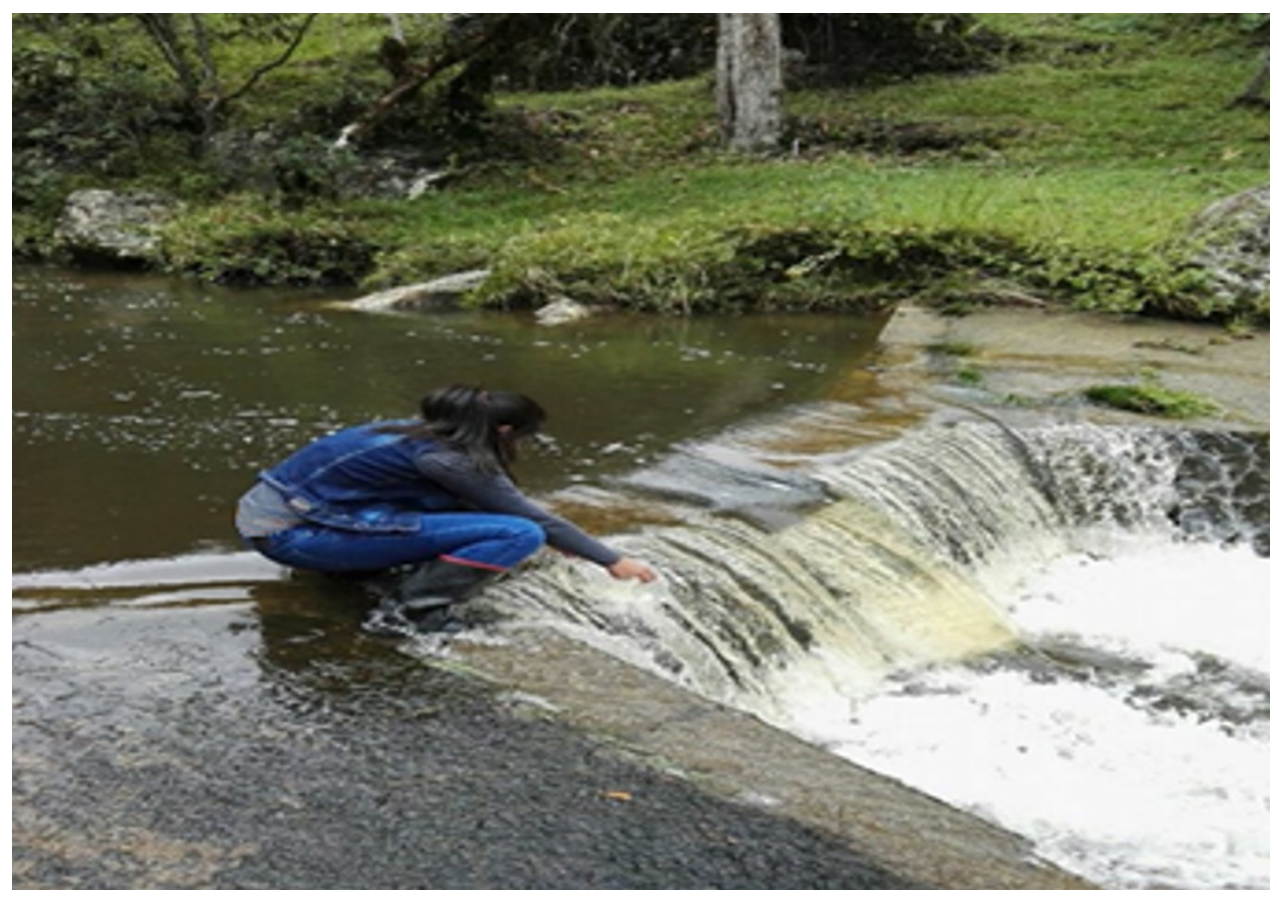

Fuente: Elaboración propia.

Figura 3. Recolección agua de grifo.

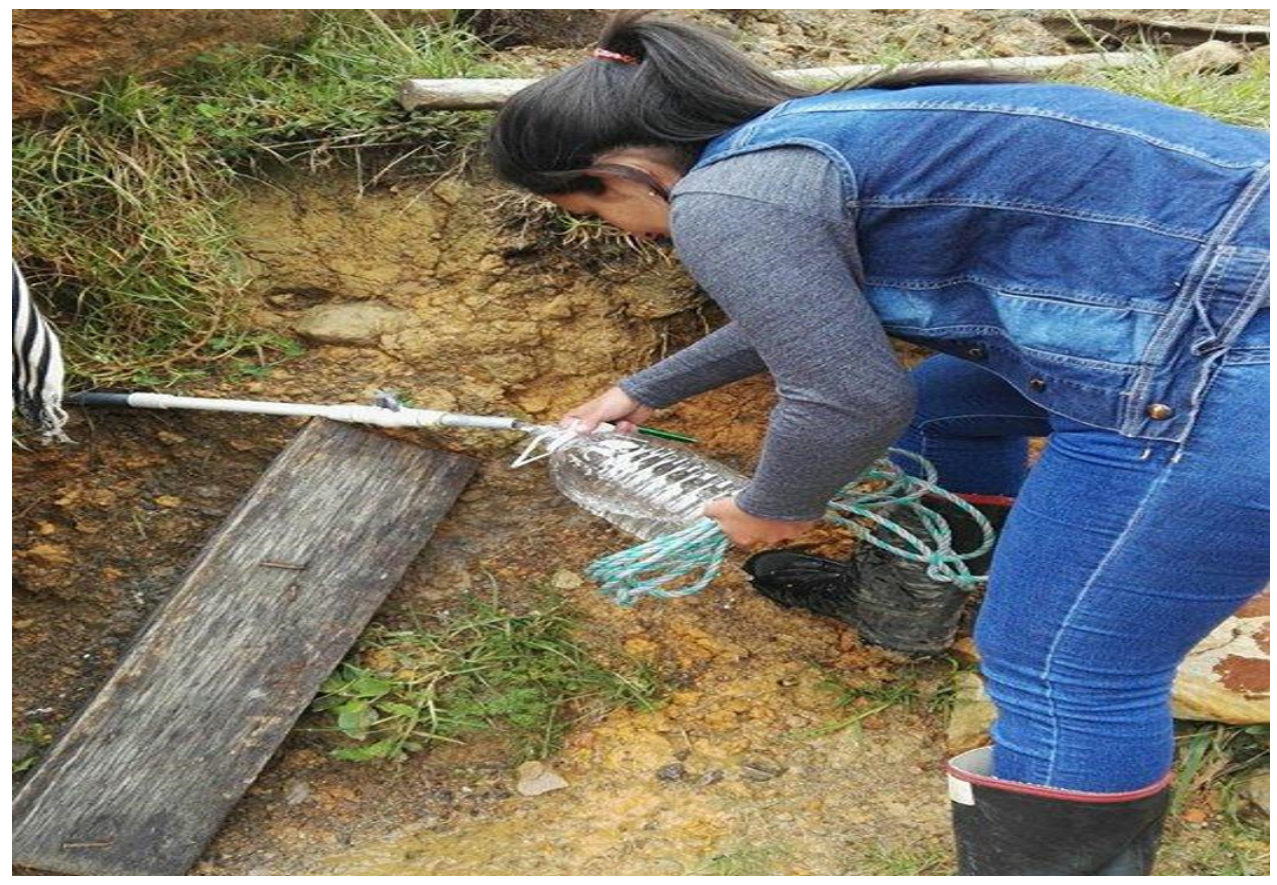

Fuente: Elaboración propia. 


\section{Análisis físico-químico}

El análisis físico-químico se realizó teniendo en cuenta los parámetros establecidos en la Resolución 2115 de 2007 (20). La muestra se tomó de la casa 1 debido que es la primera vivienda en la que deriva la alimentación de las quebradas a la vereda Río Suárez y así determinar más claramente las características físico-químicas que tiene el agua al ingresar a la red de distribución. Este análisis se realizó en el laboratorio especializado en análisis de aguas Hidrolab.

\section{Análisis Microbiológico}

\section{Filtración por membrana}

El método de filtración por membrana es altamente reproducible y es usado para el monitoreo de agua. El protocolo utilizado fue el establecido en el Standard Methods $9222(21)$.

- El procedimiento se realiza bajo las normas de esterilidad y asepsia recomendadas. Se esterilizo todo el equipo de filtración, y se pasó $100 \mathrm{ml}$ de agua destilada estéril para limpiar el equipo antes de iniciar el filtrado de las muestras, el agua destilada estéril se pasó, antes del procesamiento de cada muestra.

- Se ubica la membrana de $0.45 \mathrm{~mm}$ con unas pinzas estériles en el porta filtro del equipo y se coloca el embudo estéril.
- Se adicionan $100 \mathrm{ml}$ de la muestra, previa homogenización y se inicia la filtración.

- Terminada la filtración se retira el embudo y se toma la membrana con una pinza estéril y se siembra en cada uno de los medios (ENDO, Bilis Esculina, Cetrimide y Sabouraud) previamente hidratados.

- Los medios se incubaron a $37^{\circ} \mathrm{C}$ por 24 horas

Figura 4. Llenado de embudos con el agua a analizar.

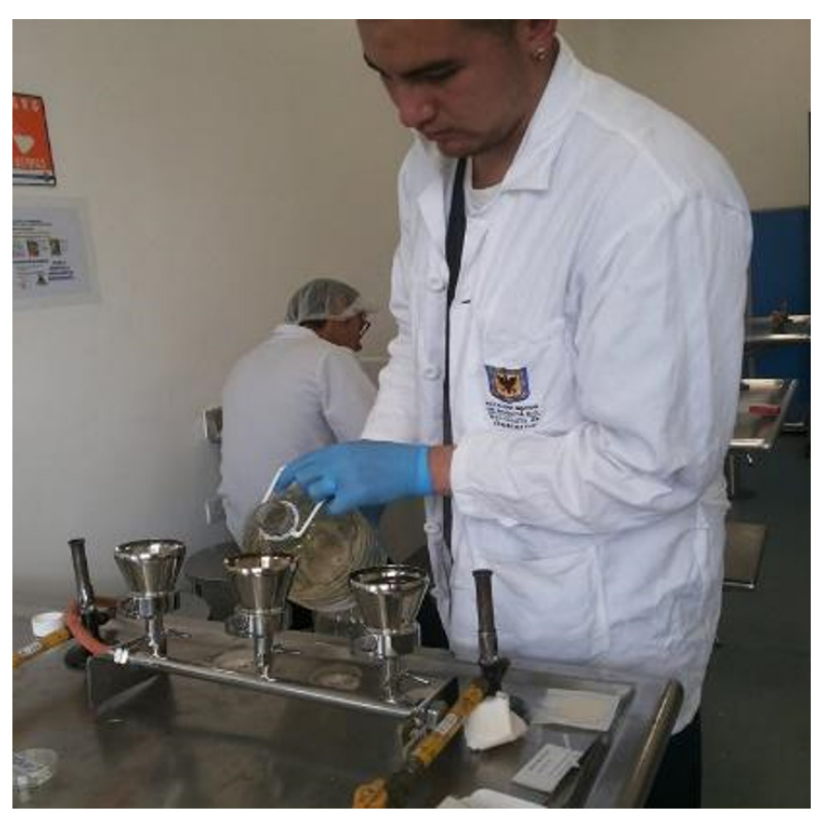

Fuente: Elaboración propia. 
Figura 5. Equipo de filtración.

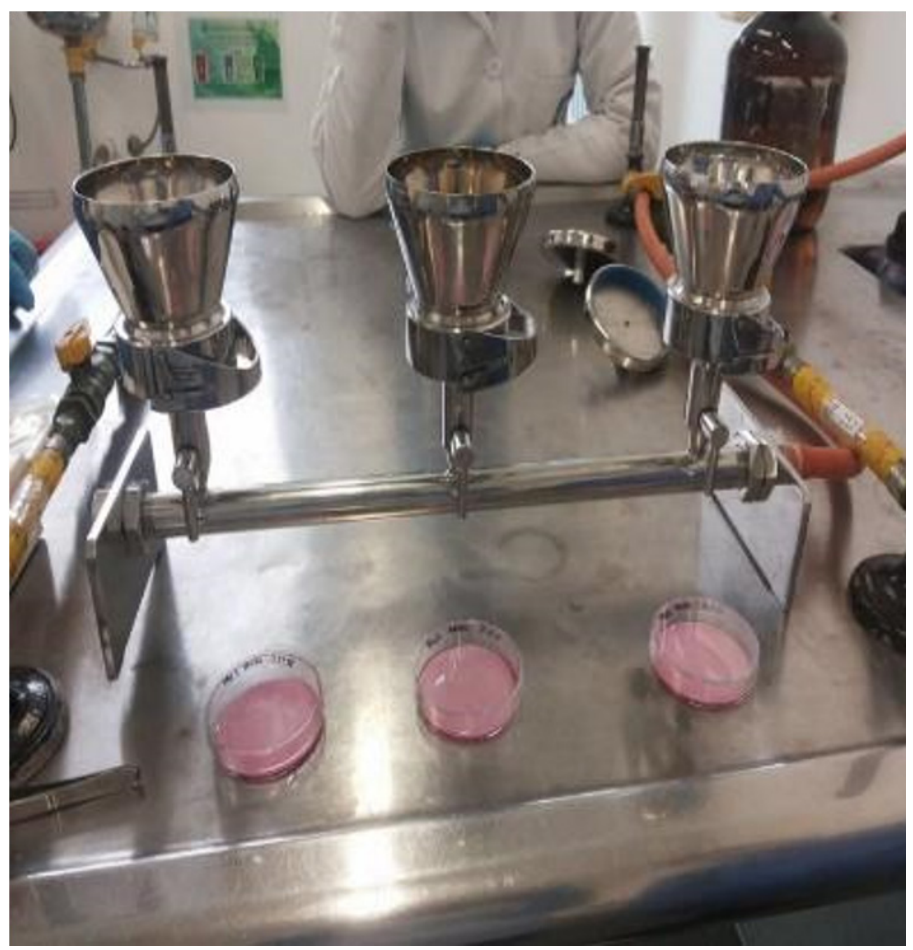

Fuente: Elaboración propia.

Figura 6. Hidratación de los medios con agua destilada estéril.

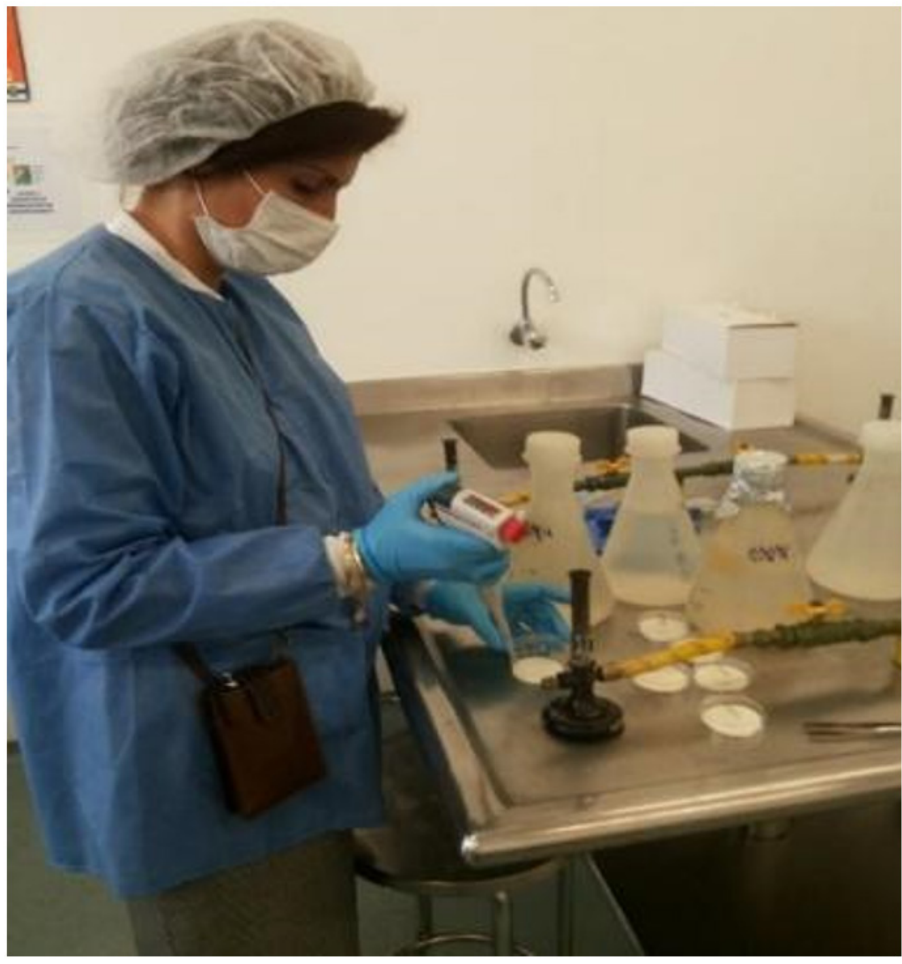

Fuente: Elaboración propia. 


\section{Recuento de UFC}

La obtención del número de unidades formadoras de colonias se realizó mediante cuenta colonias digital.

\section{Aislamiento y coloración de Gram}

Se escogieron las colonias presuntivas de coliformes, las no fermentadoras de lac- tosa y las presuntivas de hongos, las cuales fueron repicadas en agar sangre, agar MacConkey, agar King B, agar Tripticasa Soya y agar PDA, para obtener los microorganismos puros. De igual forma se les realizó la coloración de Gram.

Figura 7. Aislamiento de colonias puras.

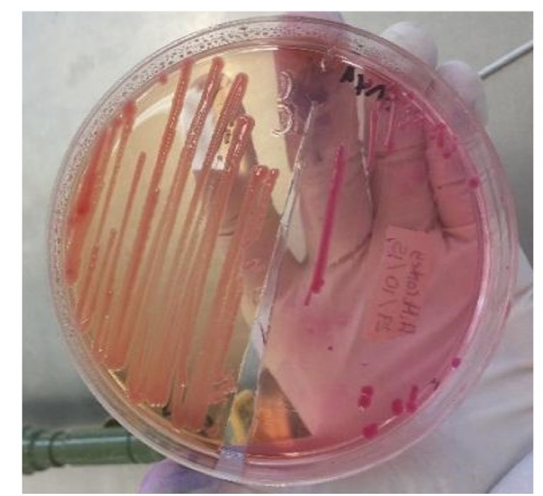

Agar MacConkey

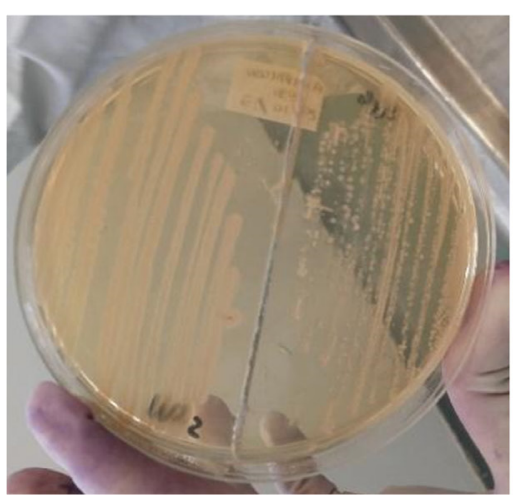

Agar Tripticasa Soya

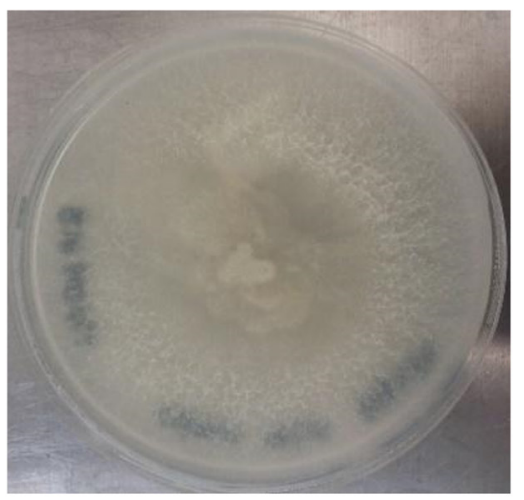

Agar PDA

Fuente: Elaboración propia.

Figura 8. Coloración de Gram aumento 100x.

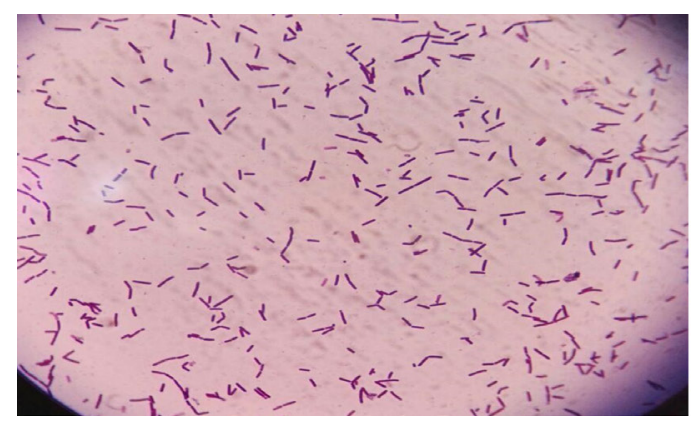

Bacilos Gram +

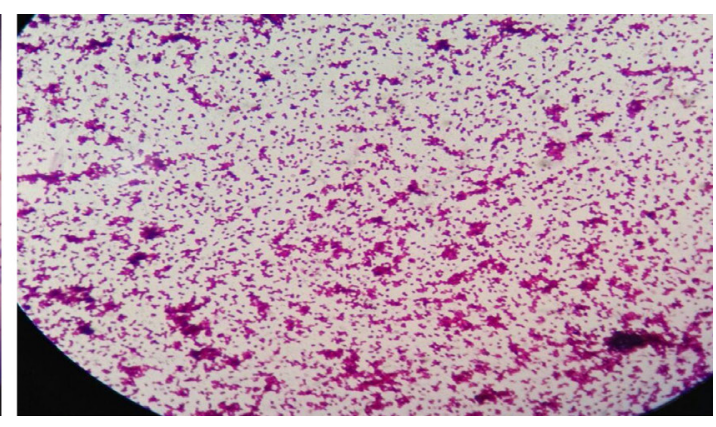

Cocos Gram +

Fuente: Elaboración propia. 


\section{Identificación bioquímica}

La identificación bioquímica de las bacterias aisladas se realizó por el método $\mathrm{BD}$ BBL CrystalTM para Gram positivos y Gram negativos.

\section{Identificación de hongos}

La identificación de género y posible especie de los hongos aislados se realizó mediante las claves dicótomas teniendo en cuenta sus características microscópicas con la tinción de azul de lactofenol para identificar las estructuras micóticas y macroscópicas como aspecto de la colonia, color y micelio, entre otros.

Figura 9. Tinción Azul de Lactofenol aumento 40x.

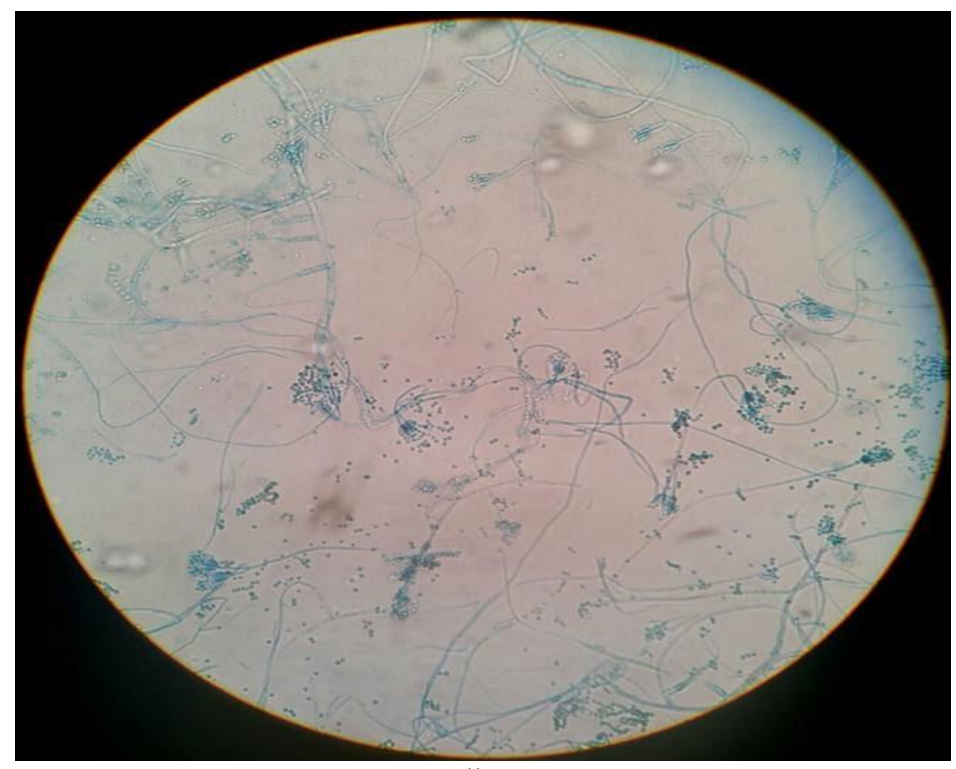

Penicillum spp

Fuente: Elaboración propia.

\section{Resultados}

\section{Análisis fisicoquímico}

Los resultados obtenidos a partir de los análisis físico-químicos realizados por el labo- ratorio especializado Hidrolab se describen en la tabla 2 , en la cual se observan los parámetros analizados y los valores máximos aceptables establecidos en la resolución 2115 de 2007. 
Tabla 2. Resultados de los parámetros físico-químico evaluados y valores máximos aceptables.

\begin{tabular}{|l|l|l|}
\hline Parámetro & Resultados & Valor máximo aceptable \\
\hline Cloruros & $<3.0 \mathrm{mg} / \mathrm{L}$ & $250 \mathrm{mg} / \mathrm{L}$ \\
\hline $\mathrm{pH}$ & $7.21\left(19.3^{\circ} \mathrm{C}\right)$ & $6.5-9.0$ \\
\hline Sulfato & $<1 \mathrm{mg} / \mathrm{L}$ & $250 \mathrm{mg} / \mathrm{L}$ \\
\hline Hierro & $0.47 \mathrm{mg} / \mathrm{L}$ & $0.3 \mathrm{mg} / \mathrm{L}$ \\
\hline Alcalinidad & $12 \mathrm{mg} / \mathrm{L}$ & $200 \mathrm{mg} / \mathrm{L}$ \\
\hline Color aparente & $5(\mathrm{pH}: 6.56)$ & $15 \mathrm{UPC}$ \\
\hline Conductividad & $50 \mathrm{~S} / \mathrm{cm}$ & $1000 \mathrm{~S} / \mathrm{cm}$ \\
\hline Dureza total & $12.6 \mathrm{mg} / \mathrm{L}$ & $300 \mathrm{mg} / \mathrm{L}$ \\
\hline Turbiedad & $12.6 \mathrm{UNT}$ & $2 \mathrm{UNT}$ \\
\hline
\end{tabular}

Fuente: Elaboración propia.

Los resultados muestran una cuantificación de hierro por encima del valor máximo aceptable, así como el nivel de turbiedad inadecuado que pueden afectar el sabor y el aspecto del agua.

\section{Análisis Microbiológico}

Dentro de las muestras se observó un alto recuento de Streptococcus del grupo D, en el medio bilis esculina, dato que se obtuvo en todos los puntos del muestreo con un número >300 UFC/100 ml.

En medio cetrimide se observó recuento >300 UFC/100 ml en todos los puntos muestreados indicando alta probabilidad de la presencia del género Pseudomonas.

En el medio ENDO se identificaron coliformes con crecimiento $>300 \mathrm{UFC} / 100 \mathrm{ml}$

El recuento de hongos más alto se obtuvo en la casa 1 con $240 \mathrm{UFC} / 100 \mathrm{ml}$.

En la tabla 3, se observan los recuentos bacterianos y micóticos obtenidos en cada uno de los puntos de muestreo.

Tabla 3. Recuento bacteriano y micótico en UFC/100 ml del Río Suárez con relación a lo establecido en la Resolución 2115 de 2007 (menor de 0).

\begin{tabular}{|l|l|l|l|l|}
\hline PUNTOS DE MUESTREO & ENDO (Coliformes) & $\begin{array}{l}\text { BILIS ESCULINA } \\
\text { (Streptococcus del } \\
\text { grupo D) }\end{array}$ & $\begin{array}{l}\text { CETRIMDE } \\
\text { (Pseudomonas) }\end{array}$ & $\begin{array}{l}\text { SABOURAUD } \\
\text { (Hongos) }\end{array}$ \\
\hline Quebrada 1 & $>300 \mathrm{UFC} / 100 \mathrm{ml}$ & $>300 \mathrm{UFC} / 100 \mathrm{ml}$ & $>300 \mathrm{UFC} / 100 \mathrm{ml}$ & $>300 \mathrm{UFC} / 100 \mathrm{ml}$ \\
\hline Quebrada 2 & $>300 \mathrm{UFC} / 100 \mathrm{ml}$ & $>300 \mathrm{UFC} / 100 \mathrm{ml}$ & $>300 \mathrm{UFC} / 100 \mathrm{ml}$ & $>300 \mathrm{UFC} / 100 \mathrm{ml}$ \\
\hline Quebrada 3 & $>300 \mathrm{UFC} / 100 \mathrm{ml}$ & $>300 \mathrm{UFC} / 100 \mathrm{ml}$ & $>300 \mathrm{UFC} / 100 \mathrm{ml}$ & $180 \mathrm{UFC} / 100 \mathrm{ml}$ \\
\hline Casa 1 & $>300 \mathrm{UFC} / 100 \mathrm{ml}$ & $>300 \mathrm{UFC} / 100 \mathrm{ml}$ & $>300 \mathrm{UFC} / 100 \mathrm{ml}$ & $240 \mathrm{UFC} / 100 \mathrm{ml}$ \\
\hline Casa 2 & $220 \mathrm{UFC} / 100 \mathrm{ml}$ & $>300 \mathrm{UFC} / 100 \mathrm{ml}$ & $>300 \mathrm{UFC} / 100 \mathrm{ml}$ & $120 \mathrm{UFC} / 100 \mathrm{ml}$ \\
\hline
\end{tabular}




\begin{tabular}{|l|l|l|l|l|}
\hline PUNTOS DE MUESTREO & ENDO (Coliformes) & $\begin{array}{l}\text { BILIS ESCULINA } \\
\text { (Streptococcus del } \\
\text { grupo D) }\end{array}$ & $\begin{array}{l}\text { CETRIMDE } \\
\text { (Pseudomonas) }\end{array}$ & $\begin{array}{l}\text { SABOURAUD } \\
\text { (Hongos) }\end{array}$ \\
\hline Casa 3 & $>300 \mathrm{UFC} / 100 \mathrm{ml}$ & $>300 \mathrm{UFC} / 100 \mathrm{ml}$ & $>300 \mathrm{UFC} / 100 \mathrm{ml}$ & $120 \mathrm{UFC} / 100 \mathrm{ml}$ \\
\hline Casa 4 & $>300 \mathrm{UFC} / 100 \mathrm{ml}$ & $>300 \mathrm{UFC} / 100 \mathrm{ml}$ & $>300 \mathrm{UFC} / 100 \mathrm{ml}$ & $160 \mathrm{UFC} / 100 \mathrm{ml}$ \\
\hline Casa 5 & $>300 \mathrm{UFC} / 100 \mathrm{ml}$ & $>300 \mathrm{UFC} / 100 \mathrm{ml}$ & $>300 \mathrm{UFC} / 100 \mathrm{ml}$ & $88 \mathrm{UFC} / 100 \mathrm{ml}$ \\
\hline Casa 6 & $>300 \mathrm{UFC} / 100 \mathrm{ml}$ & $>300 \mathrm{UFC} / 100 \mathrm{ml}$ & $>300 \mathrm{UFC} / 100 \mathrm{ml}$ & $72 \mathrm{UFC} / 100 \mathrm{ml}$ \\
\hline Casa 7 & $>300 \mathrm{UFC} / 100 \mathrm{ml}$ & $>300 \mathrm{UFC} / 100 \mathrm{ml}$ & $>300 \mathrm{UFC} / 100 \mathrm{ml}$ & $108 \mathrm{UFC} / 100 \mathrm{ml}$ \\
\hline
\end{tabular}

Fuente: Elaboración propia.

Tabla 4. Microorganismos identificados por la técnica BD BBL Crystal ${ }^{\mathrm{TM}}$.

\begin{tabular}{|l|l|}
\hline PUNTOS DE MUESTREO & MICROORGANIISMOS AISLADO \\
\hline Quebrada 1 & $\begin{array}{l}\text { Bacillus subtilis } \\
\text { Pseudomonas aeruginosa }\end{array}$ \\
\hline Quebrada 2 & $\begin{array}{l}\text { Corynebacterium bovis } \\
\text { Escherichia coli }\end{array}$ \\
\hline Quebrada 3 & Serratia marcescens \\
\hline Casa 1 & Bacillus cereus \\
\hline Casa 2 & Aerococcus urinae \\
\hline Casa 3 & $\begin{array}{l}\text { Streptococcus bovis } \\
\text { Escherichia coli }\end{array}$ \\
\hline Casa 4 & Micrococcus sedentarius \\
\hline Casa 5 & $\begin{array}{l}\text { Enterobacter cloacae } \\
\text { Serratia marcescens }\end{array}$ \\
\hline Casa 6 & $\begin{array}{l}\text { Escherichia coli } \\
\text { Streptococcus bovis }\end{array}$ \\
\hline Casa 7 & $\begin{array}{l}\text { Escherichia coli } \\
\text { Klebsiella oxytoca }\end{array}$ \\
\hline
\end{tabular}

Fuente: Elaboración propia.

\section{Calculo del IRCA}

Los parámetros alterados que indican el índice de riesgo del agua están estipulados en el Artículo 14 de la Resolución 2115 del 2007.(20)

\section{El cálculo del Índice de Riesgo de la Calidad del Agua (IRCA) para consumo humano, se obtiene mediante la siguiente formula:}

$\mathrm{IRCA}=\frac{\text { Sumatoria del puntaje de los parámetros alterados }}{100} \times 100$ 
Tabla 5. Parámetros alterados identificados de importancia en el índice de riesgo de la calidad del agua de la vereda Río Suárez.

\begin{tabular}{|l|l|}
\hline Parámetro & Puntaje de riesgo \\
\hline Turbiedad & 15 \\
\hline Hierro & 1.5 \\
\hline Coliformes Totales & 15 \\
\hline E. coli & 25 \\
\hline
\end{tabular}

Fuente: Elaboración propia.

Tabla 6. Clasificación según el IRCA (Índice de Riesgo de la Calidad de Agua) por muestra.

\begin{tabular}{|l|l|l|l|}
\hline \multicolumn{1}{|c|}{ Muestra } & \multicolumn{1}{|c|}{ Parámetros } & \multicolumn{1}{c|}{$\begin{array}{c}\text { Puntaje de } \\
\text { riesgo IRCA }\end{array}$} & $\begin{array}{c}\text { Clasificación } \\
\text { según el IRCA }\end{array}$ \\
\hline Casa 1 & $\begin{array}{l}\text { Turbiedad } \\
\text { Hierro } \\
\text { Coliformes totales }\end{array}$ & 31.5 & Medio \\
\hline Casa 2 & Coliformes totales & 15 & Medio \\
\hline Casa 3 & $\begin{array}{l}\text { E.coli } \\
\text { Coliformes totales }\end{array}$ & 40 & Alto \\
\hline Casa 4 & $\begin{array}{l}\text { Coliformes totales } \\
\text { Casa 5 }\end{array}$ & 15 & Medio \\
\hline Casa 6 & $\begin{array}{l}\text { Coliformes totales } \\
\text { E.coli }\end{array}$ & 15 & Medio \\
\hline Casa 7 & $\begin{array}{l}\text { Coliformes totales } \\
\text { E.coli }\end{array}$ & 40 & Alto \\
\hline
\end{tabular}

Fuente: Elaboración propia.

La resolución 2115 de 2007, establece que el agua de consumo humano con un porcentaje de clasificación IRCA entre 35.1\% y $80 \%$ se cataloga como un índice de riesgo alto y un puntaje entre $14.1 \%$ a $35 \%$ corresponde a un índice de riesgo medio, por lo tanto se debe notificar a la autoridad sanitaria correspondiente inmediatamente. Los hongos aislados en medio PDA pertenecen al phylum Ascomycota, los cuales se clasifican como microorganismos ambientales. 
Tabla 7. Identificación de hongos .

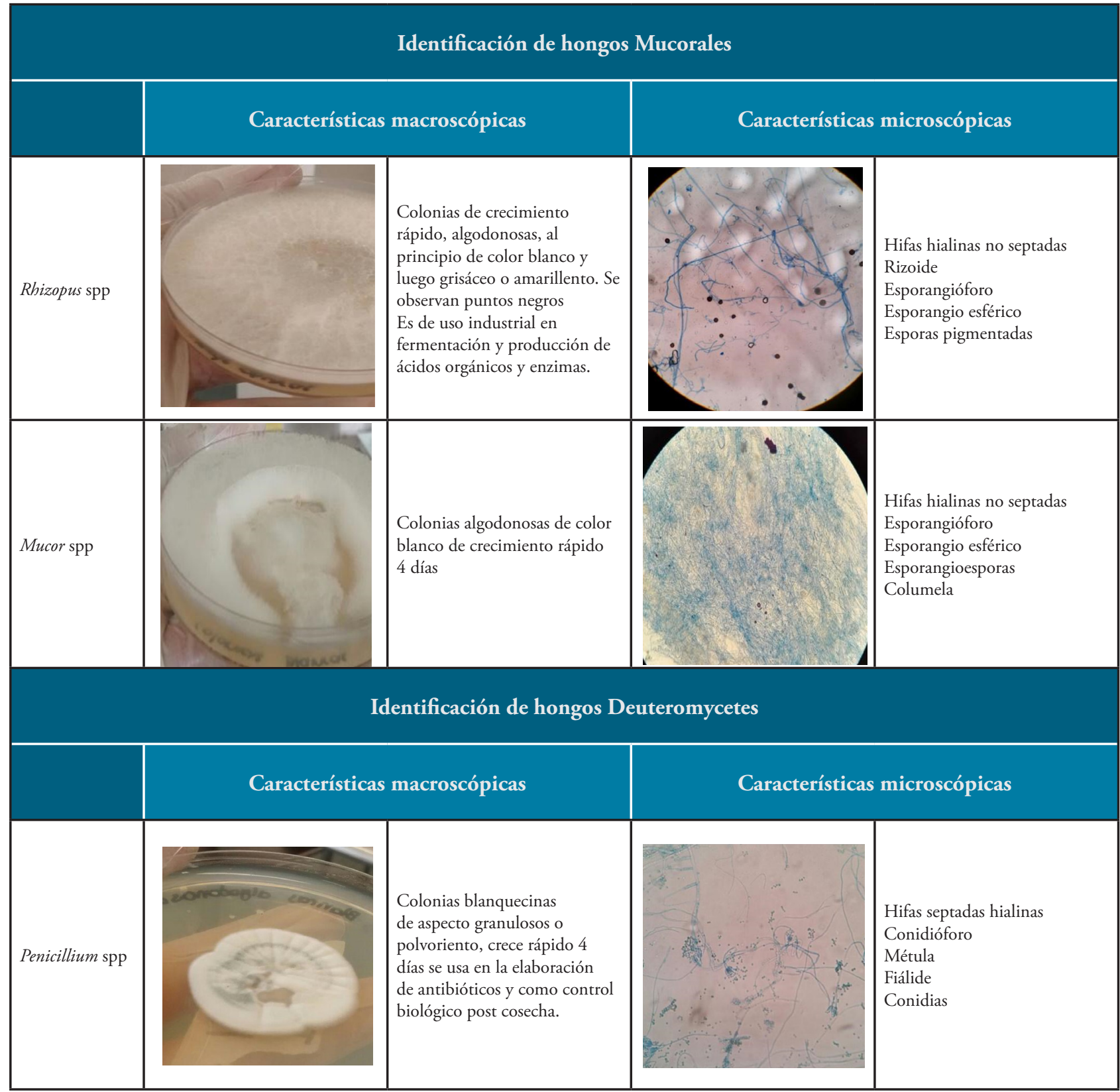

Fuente: Elaboración propia.

\section{Discusión}

Este estudio es el primer acercamiento a la evaluación fisicoquímica y microbiológica de la calidad del agua para consumo humano en la vereda Río Suárez (Puente Nacional, Santander), se seleccionó este punto en el trayecto del Río Suárez porque el Instituto de Hidrología, Meteorología y Estudios Ambientales (IDEAM) no registra ningún 
antecedente de estudio, esta agua no recibe ningún tratamiento y abastece a cerca de 1000 personas habitantes de la vereda Río Suárez.

El análisis físico químico evidenció que el hierro está por encima de lo permitido, según lo establece la resolución 2115 de 2007. De acuerdo con estudios realizados la concentración de hierro elevada puede afectar el sabor del agua, producir manchas indelebles sobre los artefactos sanitarios y la ropa blanca. El hierro en solución contribuye con el desarrollo de microorganismos que pueden formar depósitos de óxido férrico en la red de distribución (22) y se asocia con alteraciones en la turbiedad del agua (23). Un estudio con resultados similares fue realizado en aguas subterráneas de la provincia del Chaco Argentina donde encontraron que la mayoría de las muestras tenían una concentración promedio de 0.44 $\mathrm{mg} / \mathrm{L}$ de hierro, mostrando la posibilidad que al filtrarse el agua por el suelo y piedras puede desprender sustancias, disolver minerales y así corroer las tuberías de distribución del agua (24).

Los procesos de microfiltrado se utilizan para disminuir los niveles de turbiedad del agua, esto se demuestra en un estudio realizado en el municipio de Bojacá, Cundinamarca cuyos resultados arrojaron niveles de turbiedad normales en donde se utilizó este método (25), a comparación de los resultados obtenidos en este estudio en el cual los niveles de turbiedad superan ampliamente el valor establecido en la resolución 2115 de
2007 (2 unidades nefelométricas de turbiedad UNT) con 12.6 UNT, lo cual se debe posiblemente a la presencia de partículas en suspensión o coloides como arcillas, limo, tierra finamente dividida y la presencia de microorganismos (22), la turbiedad ha sido una característica ampliamente aplicada como criterio de calidad del agua, tanto en las fuentes de abastecimiento como en los procesos de potabilización y sistemas de distribución (26).

Los coliformes totales pertenecen a un grupo de microorganismos utilizados como indicadores de contaminación de aguas, su hallazgo indica un impacto negativo en la calidad sanitaria del agua (27). Los datos obtenidos en el recuento de coliformes totales en las aguas de la vereda Río Suárez, superan los valores aceptables establecidos en la resolución 2115 de 2007, la presencia de estos microrganismos en el agua podrían ser causa de graves problemas de salud de tipo urinario, gastrontestinal y de piel entre otros.

En todas las muestras se aislaron microorganismos presuntivamente patógenos como Escherichia coli, Klebsiella oxytoca, que se pueden hallar en la flora intestinal tanto humana como animal $(28,29)$.

El índice de riesgo de la calidad del agua para consumo humano (IRCA), calculado en el presente estudio obtuvo puntajes que la clasifican entre riesgo medio y alto. En todas las muestras se encontraron coliformes totales en elevadas concentraciones 
y $E$. coli solo en el agua de tres viviendas (casa 3, casa 6 y casa 7) que otorga mayores puntajes para clasificarlas como agua de alto riesgo para el consumo humano según el Índice de Riesgo de la Calidad del Agua (IRCA) con una valoración de 40 que podría indicar contaminación fecal; las casas 2, 4 y 5 se clasificaron como aguas de riesgo medio para el consumo humano ya que solo tuvieron el puntaje asignado a Coliformes totales según la resolución 2115 de 2007. Es de anotar que en una de las muestras provenientes de origen (quebrada Villamil -muestra 2), se encontró E. coli.

Según lo establecido en la normatividad al obtener puntajes de medio y alto riesgo en aguas para uso y consumo humano, se debe informar a la persona o ente prestador del servicio, COVE, Alcaldía y / o Gobernación.

En este estudio se identificaron otras bacterias como Serratia marcescens, la cual se encuentra en tierra y medio ambiente (30), Pseudomonas aeruginosa se ha visto asociada a infecciones nosocomiales, pero también se puede encontrar en el medio ambiente, en vegetales y frutas (31), Bacillus subtilis y Bacillus cereus se han encontrado en medio ambiente principalmente, aunque también en agua y tierra (32), Corynebacterium bovis, Aerococcus urinae y Streptococcus porcinus son bacterias que probablemente estén asociadas a la presencia de animales cerca de las fuentes que abastecen la población como bovinos, porcinos y aves, estas bacterias pueden llegar a causar endocardi- tis y bacteremias, en personas con predisposición (33-35). Micrococcus sedentarius se puede encontrar como saprofito ambiental y en la piel (36) y Enterobacter cloacae que se encuentra principalmente como microbiota normal del tracto digestivo, también puede provocar infecciones del aparato urinario y en algunos casos bacteremia (37), esto podría indicar que la contaminación puede provenir de diversas fuentes ambientales como los cultivos de frutas hallados en las orillas de las quebradas, tierra y vegetales; algunos microorganismos pueden provenir de fuentes animales, ya que también se observó la presencia de animales de pastoreo que pueden contaminar indirectamente el agua con sus desechos orgánicos como excremento y orina.

La presencia de las bacterias nombradas anteriormente puede ocasionar múltiples, afecciones en la salud humana como infecciones de tipo gastrointestinal, de piel, heridas, vías respiratorias y urinarias entre otras, sobre todo en individuos inmunosuprimidos y convertirse en un problema serio en la salud pública.

En la vereda Río Suárez existen siembras de cultivo de lulo y fresa a las orillas de las quebradas, en las cuales se observó que no hay un control en el desecho de las frutas en descomposición que se acumulan a la orilla de las quebradas, pudiendo ser causa de la presencia de hongos de origen ambiental como Mucor spp y Rhizopus spp, en el agua, situación que a su vez podría facilitar la dispersión de las conidias. Los hongos iden- 
tificados en el estudio no se asocian con enfermedad en el humano, pero si con la fruticultura, a este respecto Fraire-Cordero en su estudio "Hongos Patógenos en Fruto de Fresa (Fragaria x ananassa Duch.) en Postcosecha" demuestra cómo se involucran los hongos ambientales en los procesos de pudrición de la fruta en especial fresa, algunos de los microorganismos aislados en su estudio fueron Aspergillus, Botrytis, Colletotrichum, Geotrichum, Mucor, Penicillium, Pestalotiopsis, Phytophthora, y Rhizopus stolonifer; identificados como hongos saprofíticos (38) y por su parte Koike \& Bolda, en su estudio pudrición de fruta por Rhrizopus y Mucor en la fresa, muestran resultados similares (39)

\section{Conclusiones}

La evaluación realizada a las características microbiológicas y físico-químicas del agua de la vereda Río Suárez de municipio de Puente Nacional-Santander, evidencio que en todos los puntos de muestreo los parámetros estudiados sobrepasan los rangos normales aptos para que el agua pueda ser utilizada con seguridad por la población.

El análisis físico-químico dio a conocer que el agua en estudio presenta valores de hierro mayor a $0.3 \mathrm{mg} / \mathrm{L}$ y turbiedad mayor a 2 UNT, los cuales pueden afectar el sabor y el aspecto del agua respectivamente.
Los análisis realizados con el método filtración por membrana, demostraron recuentos microbiológicos mayores a $0 \mathrm{UFC} / 100 \mathrm{ml}$ de acuerdo a la Resolución 2115 de 2007.

En el análisis microbiológico se confirmó la presencia de bacterias como Eschericha coli, Aerococcus urinae, Pseudomonas aeruginosa, Klebsiella oxytoca, Bacillus subtilis y Bacillus cereus que son potencialmente patógenos y se asocian con infecciones gastrointestinales, de piel y urinarias, entre otras.

Se identificaron hongos como Rhizopus y Mucor, estos hongos se encuentran en el ambiente y son causantes de pudrición de frutas que al ser utilizadas para riego de huertas caseras pueden trasmitir los hongos.

Al desarrollar la formula representativa del IRCA, se determinaron valores de $31.5,15$, $40,15,15,40$ y 40 que clasificaron el agua de la vereda Río Suárez en el rango de alto y medio, dando como resultado agua no apta para consumo humano de acuerdo al Decreto 1575 de 2007 y la Resolución 2115 de 2007.

\section{Referencias}

1. Neuronas PEc. portaleducativo.net. [Online].; 2018 [citado el 7 de marzo de 2019]. Disponible en: http://www.portaleducativo.net/tercero-basico/785/Los-Rios

2. IDEAM - Instituto de Hidrología, Meteorología y Estudios Ambientales. Hidrología. [Online]. 2018 [citado el 10 de marzo de 2019]. Disponible en http://www.ideam.gov.co/web/atencion-y-participacion-ciudadana/hidrologia. 
3. Corrales L, Sánchez L, Escucha F. Determinación de la presencia de bacterias patógenas para el humano en aguas de riego en la cuenca alta de la sabana de Bogotá; D.C. Colombia. NOVA 2014 vol 12, núm 22, p 179 - 186.

4. OMS. Guias para la Calidad del Agua Potable. Gideon: OMS, Missouri; 2006.

5. Programa de las naciones unidas para el desarrollo;OMS. Programa de las naciones unidas para el desarrollo. 1989.

6. Organización Mundial de la Salud. Organización Mundial de la Salud. [Online].; 2006 [citado el 1 abril de 2019]. Disponible en: http://www.who. int/water_sanitation_health/dwq/guidelines/es/

7. LENNTECH. LENNTECH. [Online]. 2019 [citado el 1 de abril de 2019]. Disponible en: http:// www.lenntech.es/aplicaciones/potable/normas/estandares-europeos-calidad-agua-potable.htm

8. EPA. [Online].; 2016 [citado el 4 de abril de 2019]. Disponible en: http://www.epa.gov/watertrain

9. García A. Colombia País Maravilloso. In Codazzi IgA, editor. Colombia País Maravilloso.

10. Esquema de ordenamiento territorial municipio de Guavata- Santander. Santander: Universidad Industrial de Santander; 2003.

11. Rojas JR. incoder. [Online].; 2012 [cited 2018 marzo 8]. Available from: http://www.incoder.gov.co/ documentos/Estrategia $\% 20 \mathrm{de} \% 20$ Desarrollo\%20 Rural/Pertiles\%20Territoriales/ADR_HOYA\%20 RIO\%20SUAREZ/Perfil\%20Territorial/CARACTERIZACION\%20SOCIO-DEMOGRAFICA\%20HOYA\%20DEL\%20RIO\%20SUAREZ. pdf

12. Nullvalue. RÍO SUÁREZ FOCO DE INFECCIÓN. El Tiempo. 1996 febrero 2.

13. Vega WF. Un torrente de aguas negras. El Tiempo. 2005 Enero 16.

14. Universidad Industrial de Santander CdER. esquema de ordenamiento territorial de Barbosa. sintesis. barbosa: Universidad Industrial de Santander, Centro de Estudios Regionales; 2009.
15. Pinto PA. vanguardia.com. [Online]. Puente Nacional; 2012 [cited 2018 marzo 8]. Available from: http:// www.vanguardia.com/santander/velez/145147-alarma-por-contaminacion-del-agua-que-abastece-a-puente-nacional

16. Peña PC. hsbnoticias.com. [Online].; 2014 [cited 2018 marzo 8]. Available from: http://hsbnoticias. $\mathrm{com} /$ noticias/nacional/alerta-por-derrame-de-petr\%C3\%B3leo-en-r\%C3\%ADo-suarez-100929.

17. IDEAM - CorpoMagdalena. Estudio ambiental de la cuenca Magdalena - Cauca y elementos para su ordenamiento territorial. Bogotá. 2001

18. Google.com. [Online].; 2016 [cited 2018 marzo 5]. Available from: https://www.google.com. $\mathrm{co} / \mathrm{maps} / \mathrm{place} / \mathrm{Vda} .+\mathrm{Rio}+\mathrm{Suarez},+$ Puente $+\mathrm{Nacio}-$ nal,+Santander/@5.9334123,-73.6378885,12z/da$\mathrm{ta}=! 4 \mathrm{~m} 2 ! 3 \mathrm{~m} 1 ! 1 \mathrm{~s} 0 \times 8 \mathrm{e} 41 \mathrm{e} 85 \mathrm{ea} 6735 \mathrm{ec} 9: 0 \times 1086 \mathrm{c} 2 \mathrm{c}-$ $35176 f 36 b$.

19. Instituto Nacional de Salud I. Instituto Nacional de Salud. [Online].; 2011 [cited 2018 Abril 20]. Available from: http://www.ins.gov.co/sivicap/Normatividad/2011\%20Manual\%20toma\%20de\%20 muestras $\% 20$ agua.pdf? Mobile $=1 \&$ Source $=\% 2 \mathrm{~F}$ sivicap\%2F_layouts\%2Fmobile\%2Fview.aspx\%3FList\%3Ddc462e4b-5de8-4a2f-be3a-08ad1c837db7\%26View\%3D0ac5f5c5-4988-442d-bc0e2c07af4f66a5\%26CurrentPage.

20. Ministerio de la Protección Social MDAVYDT. Resolución Número 2115 de 2007. In Por medio de la cual se señalan características, instrumentos básicos y frecuencias del sistema de control y vigilancia para la calidad del agua para consumo humano; 2007; Bogota. p. 1 - 8.

21. APHA WA. American Public Health Association (APHA). 1998. APHA (2005) Standard Methods for the Examination of Water and Wastewater. 21st Edition, American Public Health Association/ American Water Works Association/Water Environment Federation, Washington DC.

22. McFarland ML. [Online].; 2013 [cited 2018 Abril 26]. Available from: http://texaswater.tamu.edu/ resources/factsheets/15451sironandman.pdf. 
23. Martel AB. Aspectos fisicoquimicos de la calidad del agua. [Online].; 2012 [cited 2018 Marzo 26]. Available from: http://www.bvsde.paho.org/bvsatr/ fulltext/tratamiento/manualI/tomoI/uno.pdf.

24. Giménez P. Evaluación de los Niveles de Hierro y Arsénico en Aguas Naturales Subterráneas de la Región Centro-Oeste de la Provincia del Chaco Argentina. informacion tecnologica. 2006; 17(3).

25. Sandra Monica E. Calidad físicoquímica microbiológica del agua del municipio de Bojacá, Cundinamarca. NOVA. 2010;8(14).

26. Carolina Montoya DLPTCHCJCE. Efecto del incremento en la turbiedad del agua cruda sobre la eficiecia de procesos convencionales de potabilizacion. 2011 Diciembre; 57(16).

27. Gómez F. Distribución de dos Indicadores bacterianos de calidad de agua en el Golfo de Uraba. 2008 Diembre; 11(3).

28. A J. Escherichia coli: a brief review of diarrheagenic pathotypes and their role in diarrheal diseases in Iran. Journal of Clinical Microbiology. 2012; 4(3).

29. C V. Epidemiology of Klebsiella oxytoca-Associated Diarrhea Detected by Simmons Citrate Agar Supplemented with Inositol, Tryptophan, and Bile Salts. Journal of Clinical Microbiology. 2012 mayo; 50(5).

30. Mahlen SD. Serratia Infections: from Military Experiments to Current Practice. Journal of Clinical Microbiology. 2011; 24(4).

31. Soberón G. biblioweb.tic.unam. [Online]. [cited 2018 Marzo 2]. Available from: http://www.biblioweb.tic.unam.mx/libros/microbios/Cap3/.

32. Zúñiga P. Caracterización Fisiológica de Cepas de Bacillus spp. aisladas de la Rizósfera de Papa (Solanum tuberosum). Ecologia Aplicada. 2010; 9(1).

33. www.criver.com. [Online]. Available from: http:// www.criver.com/files/pdfs/infectious-agents/rm ld_r_corynebacterium_bovis.aspx.

34. Humphries RM. In Vitro Antimicrobial Susceptibility of Aerococcus urinae. Journal of Clinical microbiology. 2014; 52(6).
35. Facklam R. Identification of Streptococcus porcinus from Human Sources. Journal of Clinical Microbiology. 1995 febrero; 33(2).

36. Sáenz Anduaga L. Infecciones Cutáneas Bacterianas. Servicio de Dermatología Hospital Militar Central. Lima, Perú. 2006; 16(1).

37. ecured.cu. [Online]. [cited 2018 Marzo 2] Available from: https://www.ecured.cu/Enterobacter cloacae.

38. Fraire-Cordero MdL. Hongos Patógenos en Fruto de Fresa (Fragaria x ananassa. Revista Mexicana de Fitopatologia. 2003 Octubre; 21(3): p. 285.

39. 39. Steven T. Koike \& Mark Bolda. Guía de Producción significado de los numerosos patógenos que causan enfermedades en la fruta . [on line] [cited 2018 agosto 6] Available from: https://ucanr. edu/blogs/fresamora/blogfiles/37849.pdf 